\title{
MODELING IN-PHASE THERMOMECHANICAL FATIGUE HYSTERESIS LOOPS OF FIBER-REINFORCED CERAMIC-MATRIX COMPOSITES
}

\author{
LI LONGBIAO \\ College of Civil Aviation, Nanjing University of Aeronautics and Astronautics, No.29 Yudao St., Nanjing 210016, PR China \\ E-mail: 1lb451@nuaa.edu.cn
}

Submitted February 25, 2018; accepted April 22, 2018

\begin{abstract}
Keywords: Ceramic-matrix composites (CMCs), Thermomechanical fatigue, Hysteresis loops, Interface shear stress
In this paper, the in-phase thermomechanical fatigue hysteresis loops of fiber-reinforced ceramic-matrix composites (CMCs) have been investigated. The relationships between the thermal cyclic temperatures, fiber/matrix interface shear stress, fiber/ matrix interface debonding/sliding and the stress/strain hysteresis loops have been established. The effects of fiber volume fraction, fatigue peak stress, matrix cracking space, fiber/matrix interface debonded energy and thermal cyclic temperature range on the in-phase thermomechanical fatigue hysteresis loops have been analyzed. The in-phase thermomechanical fatigue hysteresis loops of cross-ply SiC/MAS composite have been predicted for different applied cycle number.
\end{abstract}

\section{INTRODUCTION}

Ceramic-matrix composites (CMCs) possess high specific strength and specific modulus at elevated temperature, and are being designed and developed for hot section components in commercial aero engine. As new materials, the CMCs need to meet the airworthiness certification requirements, and it is necessary to analyze the degradation, damage, and failure mechanisms subjected to cyclic loading at different temperatures and environments. Real life applications, such as turbine blades in a turbofan engine, dictate the need to determine the mechanical behavior of this material in an environment involving both cycling loads and cycling temperature which is commonly known as thermomechanical fatigue (TMF).

Many researchers performed the experimental and theoretical investigations on the thermomechanical fatigue behavior of fiber-reinforced CMCs. Butkus et al. [2] investigated the thermomechanical fatigue behavior of unidirectional $\mathrm{SiC} / \mathrm{CAS}$ composite at elevated temperature between $550^{\circ} \mathrm{C}$ and $1100^{\circ} \mathrm{C}$. It was found that the accumulated strains in the TMF tests were greater than those for the isothermal fatigue tests under identical loading conditions. Allen and Mall [3] investigated the thermomechanical fatigue behavior of cross-ply $\mathrm{SiC} /$ /MAScomposite at the temperature range of $566^{\circ} \mathrm{C}$ and $1093^{\circ} \mathrm{C}$. It was found that the damage caused by thermomechanical fatigue with the out-of-phase is much higher than the in-phase. Xie et al. [4] investigated the thermomechanical fatigue testing of CMC plates with a hole at temperature between room temperature and $1200^{\circ} \mathrm{C}$. It was found that the fatigue life reduction depended upon the thermal and loading cycling. Mei and Cheng [5] investigated the thermal cycling response of a $2 \mathrm{D} \mathrm{C} / \mathrm{SiC}$ composite subjected to the load constraint and to displacement constraint in an oxidizing environment. It was found that the load control could develop thermal microcracks and assist in oxidizing the internal fibers, however, the displacement control reduced the crack propagations and fibers oxidation due to the increasing of compressive stress. Kim et al. [6] investigated the thermomechanical fatigue behavior of $2 \mathrm{D} \mathrm{SiC} / \mathrm{SiC}$ composite at the surface temperature of about $1235^{\circ} \mathrm{C}$. It was found that in the turbine airfoil applications, thermal stress and intermediate temperature embrittlement could be just as much damage factors in reducing the fatigue life of the CMCs as the exposure to the harsh combustion environment and mechanical loading. Cluzel et al. [7] investigated the thermomechanical mechanical behavior and lifetime modeling of self-healing CMCs by coupling of mechanical and physicochemical mechanisms. Reynaud et al. [8] investigated the effects of temperature and oxidation on the mechanical hysteresis behavior in CMCs. It was found that the temperature affects the fiber/matrix interface shear stress due to the thermal expansion coefficient mismatch between fibers and matrix. Li [9] investigated the tension-tension fatigue behavior of $\mathrm{C} / \mathrm{SiC}$ composite at room temperature and $800^{\circ} \mathrm{C}$ in air condition. The degradation rate of the fiber/ 
matrix interface shear stress at $800^{\circ} \mathrm{C}$ is much higher than that at room temperature, leading to the greatly decreasing of fatigue limit stress. The comparisons of the fiber/matrix interface shear stress degradation between $\mathrm{C} / \mathrm{SiC}$ and $\mathrm{SiC} / \mathrm{SiC}$ composite have been investigated [10]. The degradation rate depends upon the fatigue peak stress, testing temperature, interphase type and fiber preforms. Under multiple loading stress levels, the damage mechanism of the fiber/matrix interface wear at room temperature and different loading sequences affect the fiber/matrix interface debonding extent and the range of the fiber/matrix interface sliding [11, 12]; under combination of cyclic fatigue and stress-rupture loading, the fiber/matrix interface oxidation and fatigue peak stress levels affect the interface debonded and interface slip length [13]. It was found that the fatigue hysteresis loops can be used as an effective tool to monitor damage evolution in CMCs [14]. However, in the researches mentioned above, the hysteresis loops models of CMCs under combination of cyclic thermal and fatigue loading have not been developed.

In this paper, the in-phase thermomechanical fatigue hysteresis loops of fiber-reinforced $\mathrm{CMCs}$ are investigated. The relationships between the thermal cyclic temperature, fiber/matrix interface shear stress, fiber/ matrix interface debonding/sliding, and the hysteresis loops are established. The effects of fiber volume fraction, fatigue peak stress, matrix cracking space, fiber/matrix interface debonded energy and temperature range on the in-phase thermomechanical fatigue hysteresis loops are analyzed. The in-phase thermomechanical fatigue hysteresis loops of cross-ply $\mathrm{SiC} / \mathrm{MAS}$ composite are predicted for different applied cycle number.

\section{THEORY}

The testing temperature affect the mechanical behavior of $\mathrm{CMCs}$, i.e., matrix microcracking, fiber/ matrix interface debonding and thermal residual stress. The two cases would be if the load and temperature were at the same frequency and either in-phase, where the

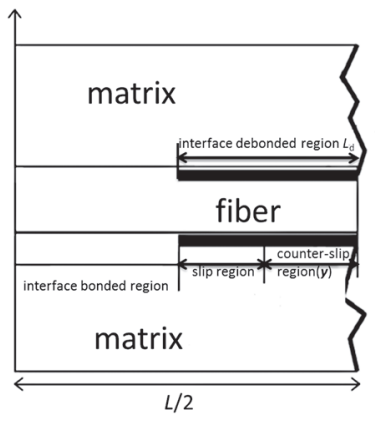

a)

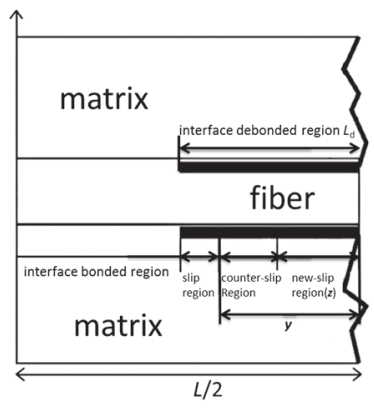

b)
Figure 1. The schematic figure for fiber slipping relative to matrix upon: a) unloading; and b) reloading. load and temperature peak together, and out-of-phase TMF, where the load peaks while the temperature is at a minimum value, and the temperature peaks while the load is at a minimum value. If the radial thermal expansion coefficient of the matrix is higher than the coefficient of the fibers, at a testing temperature $T$ lower than the processing temperature $T_{0}$, i.e., $T<T_{0}$, the radial thermal residual stresses are compressive stresses. The fiber/matrix interface shear stress can be described using the following equation.

$$
\tau_{i}=\tau_{0}+\mu \frac{\left|\alpha_{r f}-\alpha_{r m}\right|\left(T_{0}-T\right)}{A}
$$

where $\tau_{0}$ denotes the steady-state fiber/matrix interface shear stress; $\mu$ denotes the fiber/matrix interface frictional coefficient; $a_{\mathrm{rf}}$ and $a_{\mathrm{rm}}$ denote the fiber and matrix radial thermal expansion coefficient, respectively; and $A$ is a constant depending on the elastic properties of the matrix and fibers.

If matrix multicracking and fiber/matrix interface debonding are present upon first loading, the stress/strain hysteresis loops develop as a result of energy dissipation through frictional slip between fibers and the matrix upon unloading/reloading. Upon unloading, counter slip occurs in the fiber/matrix interface debonded region. The fiber/matrix interface debonded region can be divided into two regions, i.e., interface counter-slip region and interface slip region, as shown in Figure 1a. The fiber/ matrix interface counter-slip length is defined as $y$. Upon reloading, new slip occurs in the fiber/matrix interface debonded region. The interface debonded region can be divided into three regions, i.e., interface new-slip region, interface counter-slip region and interface slip region, as shown in Figure 1b. The fiber/matrix interface new-slip region is defined as $z$. When damage forms within the composite, the composite strain is described using the following equation, which assumes that the composite strain $\varepsilon_{c}$ is equivalent to the average strain in an undamaged fiber.

$$
\varepsilon_{\mathrm{c}}=\frac{2}{E_{\mathrm{f}} l_{\mathrm{c}}} \int_{l_{\mathrm{c}} / 2} \sigma_{\mathrm{f}}(x) d x-\left(\alpha_{\mathrm{lc}}-\alpha_{\mathrm{lf}}\right) \Delta \mathrm{T}
$$

where $E_{f}$ denotes the fiber elastic modulus; $\sigma_{\mathrm{f}}(x)$ denotes the fiber axial stress; $l_{\mathrm{c}}$ denotes the matrix crack spacing; $a_{\mathrm{lc}}$ and $a_{\mathrm{lf}}$ denote the composite and fiber axial thermal expansion coefficient, respectively; and DT denotes the temperature difference between fabricated temperature $T_{0}$ and test temperature $T_{1}\left(D T=T_{1}-T_{0}\right)$.

When the fiber/matrix interface partially debonds, the unloading strain $\varepsilon_{\mathrm{cu}}$ and reloading strain $\varepsilon_{\mathrm{cr}}$ are determined using the following equations.

$$
\begin{aligned}
& \varepsilon_{\mathrm{cu}}=\frac{\sigma}{V_{\mathrm{f}} E_{\mathrm{f}}}+4 \frac{\tau_{\mathrm{i}}}{E_{\mathrm{f}}} \frac{y^{2}}{r_{\mathrm{f}} l_{\mathrm{c}}}- \\
& -2 \frac{\tau_{\mathrm{i}}}{E_{\mathrm{f}}} \frac{\left(2 y-l_{\mathrm{d}}\right)\left(2 y+l_{\mathrm{d}}-l_{\mathrm{c}}\right)}{r_{\mathrm{f}} l_{\mathrm{c}}}-\left(\alpha_{\mathrm{c}}-\alpha_{\mathrm{f}}\right) \Delta \mathrm{T}
\end{aligned}
$$




$$
\begin{aligned}
& \varepsilon_{\mathrm{cr}}=\frac{\sigma}{V_{\mathrm{f}} E_{\mathrm{f}}}-4 \frac{\tau_{\mathrm{i}}}{E_{\mathrm{f}}} \frac{z^{2}}{r_{\mathrm{f}} l_{\mathrm{c}}}+4 \frac{\tau_{\mathrm{i}}}{E_{\mathrm{f}}} \frac{(y-2 z)^{2}}{r_{\mathrm{f}} l_{\mathrm{c}}}+ \\
& +2 \frac{\tau_{\mathrm{i}}}{E_{\mathrm{f}}} \frac{\left(l_{\mathrm{d}}-2 y+2 z\right)\left(l_{\mathrm{d}}+2 y-2 z-l_{\mathrm{c}}\right)}{r_{\mathrm{f}} l_{\mathrm{c}}}-\left(\alpha_{\mathrm{c}}-\alpha_{\mathrm{f}}\right) \Delta \mathrm{T}
\end{aligned}
$$

where $V_{\mathrm{f}}$ denotes the fiber volume fraction; $r_{\mathrm{f}}$ denotes the fiber radius; and $l_{\mathrm{d}}$ denots the fiber/matrix interface debonded length.

When the fiber/matrix interface completely debonds, the unloading strain $\varepsilon_{\mathrm{cu}}$ and reloading strain $\varepsilon_{\mathrm{cr}}$ are determined using the following equations.

$$
\varepsilon_{\mathrm{cu}}=\frac{\sigma}{V_{\mathrm{f}} E_{\mathrm{f}}}+4 \frac{\tau_{\mathrm{i}}}{E_{\mathrm{f}}} \frac{y^{2}}{r_{\mathrm{f}} l_{\mathrm{c}}}-2 \frac{\tau_{\mathrm{i}}}{E_{\mathrm{f}}} \frac{\left(2 y-l_{\mathrm{c}} / 2\right)^{2}}{r_{\mathrm{f}} l_{\mathrm{c}}}-\left(\alpha_{\mathrm{c}}-\alpha_{\mathrm{f}}\right) \Delta \mathrm{T}
$$

$$
\begin{aligned}
& \varepsilon_{\mathrm{cr}}=\frac{\sigma}{V_{\mathrm{f}} E_{\mathrm{f}}}-4 \frac{\tau_{\mathrm{i}}}{E_{\mathrm{f}}} \frac{z^{2}}{r_{\mathrm{f}} l_{\mathrm{c}}}+4 \frac{\tau_{\mathrm{i}}}{E_{\mathrm{f}}} \frac{(y-2 z)^{2}}{r_{\mathrm{f}} l_{\mathrm{c}}}- \\
& -2 \frac{\tau_{\mathrm{i}}}{E_{\mathrm{f}}} \frac{\left(l_{\mathrm{c}} / 2-2 y+2 z\right)^{2}}{r_{\mathrm{f}} l_{\mathrm{c}}}-\left(\alpha_{\mathrm{c}}-\alpha_{\mathrm{f}}\right) \Delta \mathrm{T}
\end{aligned}
$$

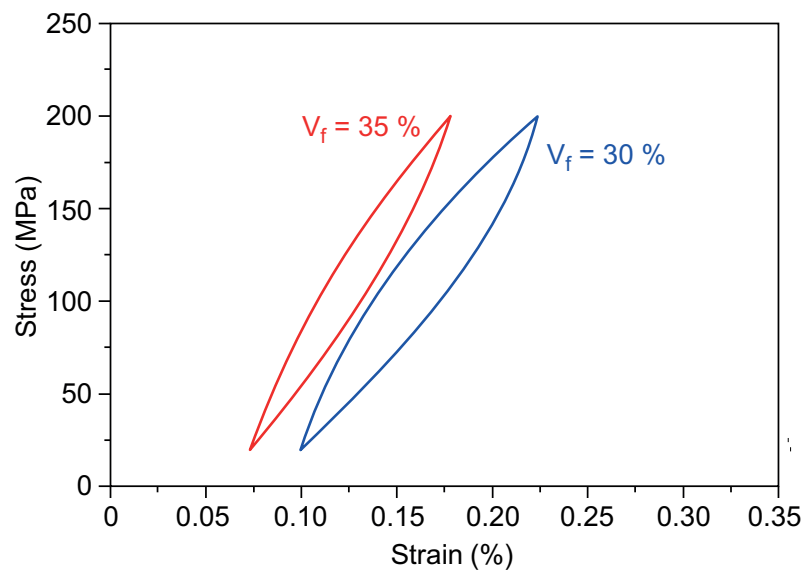

a) fatigue hysteresis loops

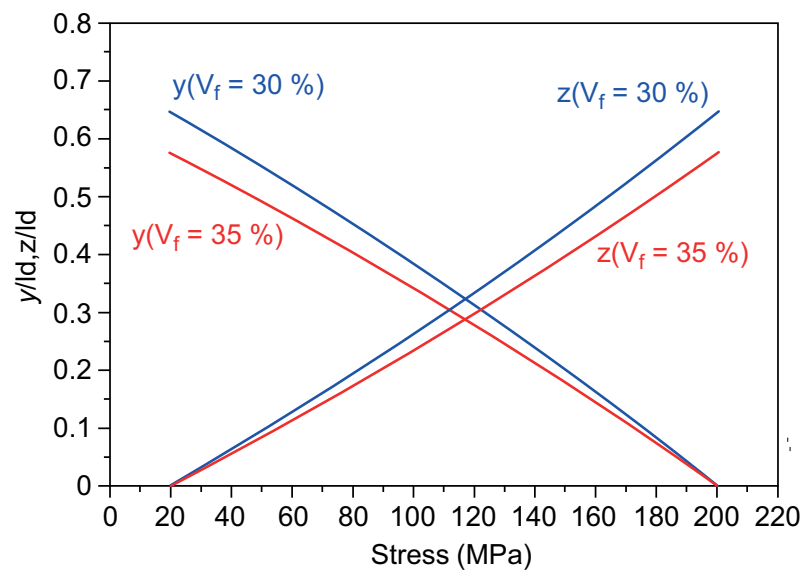

b) interface slip lengths

Figure 2. The fatigue hysteresis loops (a); the interface slip lengths (b) versus applied stress curves corresponding to different fiber volume fractions of $V_{\mathrm{f}}=30 \%$ and $35 \%$.

\section{DISCUSSION}

The ceramic composite system of $\mathrm{SiC} / \mathrm{SiC}$ is used for the case study and its material properties are given by: $V_{\mathrm{f}}=35 \%, E_{\mathrm{f}}=230 \mathrm{GPa}, E_{\mathrm{m}}=300 \mathrm{GPa}, r_{\mathrm{f}}=7.5 \mu \mathrm{m}$, $\zeta_{\mathrm{d}}=0.1 \mathrm{~J} \cdot \mathrm{m}^{-2}, \alpha_{\mathrm{rf}}=2.9 \times 10^{-6} \mathrm{~K}^{-1}, \alpha_{\mathrm{lf}}=3.9 \times 10^{-6} \mathrm{~K}^{-1}, \alpha_{\mathrm{rm}}=$ $=4.6 \times 10^{-6} \mathrm{~K}^{-1}, \alpha_{\mathrm{lm}}=2 \times 10^{-6} \mathrm{~K}^{-1}, T_{0}=1000^{\circ} \mathrm{C}, T_{1}=20^{\circ} \mathrm{C}$ and $T_{2}=800^{\circ} \mathrm{C}$. The effects of fiber volume fraction, fatigue peak stress, matrix crack spacing, interface debonded energy and temperature range on the in-phase thermomechanical fatigue stress/strain hysteresis loops, fiber/matrix interface debonding/sliding are investigated.

\section{Effect of fiber volume fraction}

The effect of fiber volume fraction (i.e., $V_{\mathrm{f}}=30 \%$ and $35 \%$ ) on the in-phase stress/strain fatigue hysteresis loops and fiber/matrix interface slip lengths at the fatigue peak stress of $\sigma_{\max }=200 \mathrm{MPa}$ and the temperature range from $20^{\circ} \mathrm{C}$ to $800^{\circ} \mathrm{C}$ are shown in Figure 2. The inphase thermomechanical fatigue stress/strain hysteresis loops for the fiber volume fraction of $V_{\mathrm{f}}=30 \%$ and

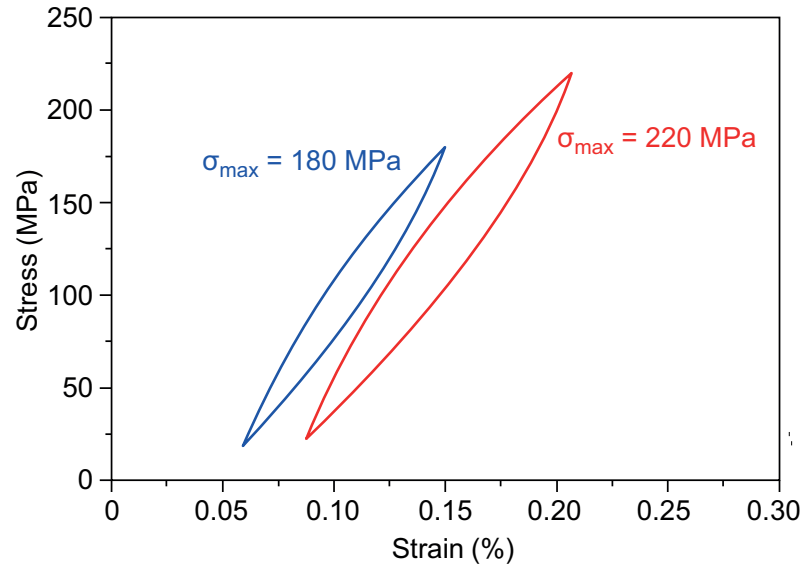

a) fatigue hysteresis loops

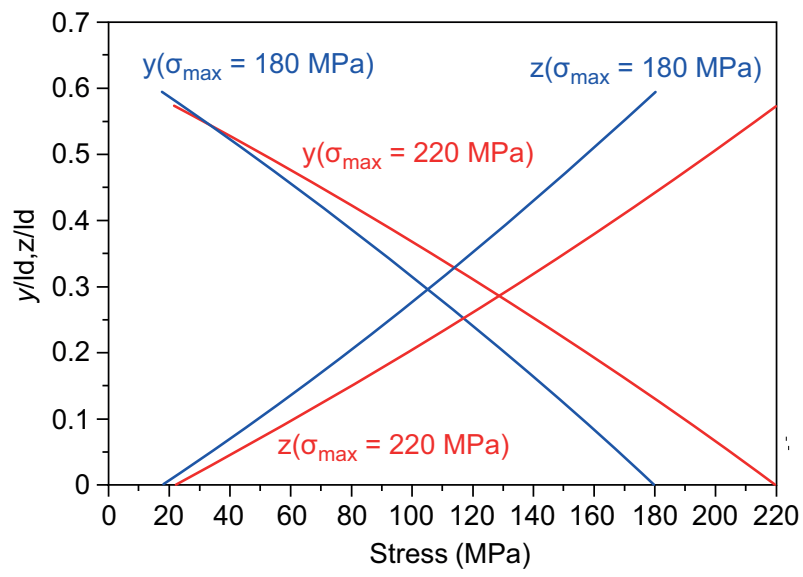

b) interface slip lengths

Figure 3. The fatigue hysteresis loops (a); the interface slip lengths (b) versus applied stress curves corresponding to different fatigue peak stresses of $\sigma_{\max }=180$ and $220 \mathrm{MPa}$. 
$35 \%$ correspond to the fiber/matrix interface partially debonding and the fiber partially sliding relative to the matrix in the interface debonded region. With increasing fiber volume fraction, the in-phase thermomechanical fatigue hysteresis loops area decreases, and the unloading residual strain decreases, as shown in Figure 2a; and the fiber/matrix interface slip lengths (i.e., $y / l_{\mathrm{d}}$ and $z / l_{\mathrm{d}}$ ) upon completely unloading or reloading to the maximum stress, decrease, i.e., from $y\left(\sigma_{\min }\right) / l_{\mathrm{d}}=z\left(\sigma_{\max }\right) / l_{\mathrm{d}}=0.64$ when $V_{\mathrm{f}}=30 \%$ to $y\left(\sigma_{\min }\right) / l_{\mathrm{d}}=z\left(\sigma_{\max }\right) / l_{\mathrm{d}}=0.57$ when $V_{\mathrm{f}}=35 \%$, as shown in Figure $2 \mathrm{~b}$.

\section{Effect of fatigue peak stress}

The effect of fatigue peak stress (i.e., $\sigma_{\max }=180$ and $220 \mathrm{MPa}$ ) on the in-phase thermomechanical fatigue stress/strain hysteresis loops and fiber/matrix interface slip lengths at the temperature range from $20^{\circ} \mathrm{C}$ to $800^{\circ} \mathrm{C}$ are shown in Figure 3. The in-phase thermomechanical fatigue stress/strain hysteresis loops for the fatigue peak stresses of $\sigma_{\max }=180$ and $220 \mathrm{MPa}$ correspond to the fiber/matrix interface partially debonding and the fiber

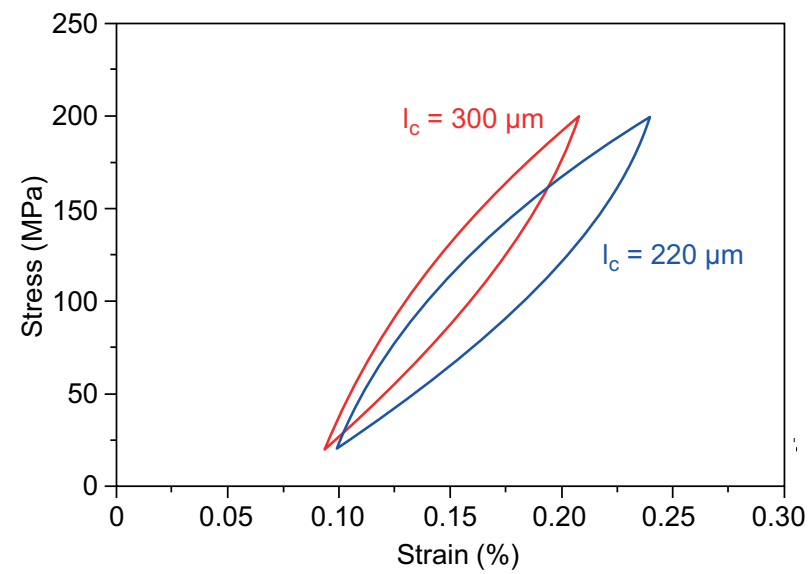

a) fatigue hysteresis loops

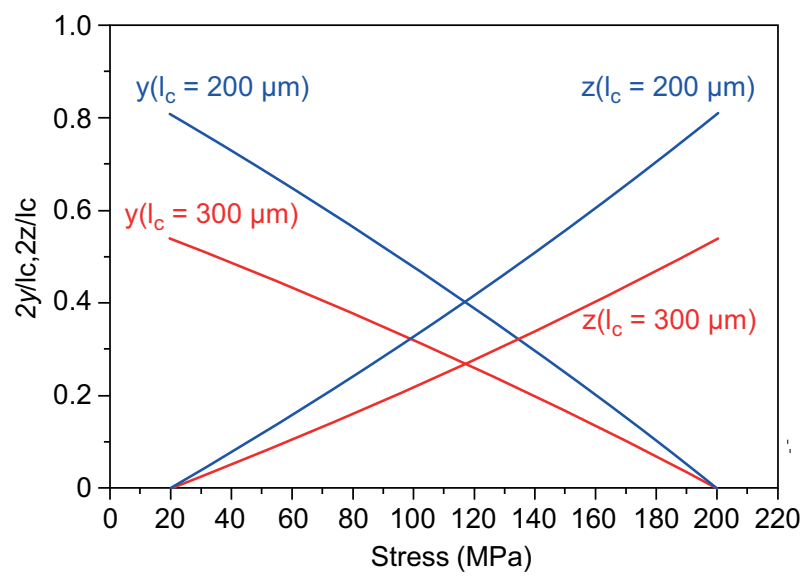

b) interface slip lengths

Figure 4. The fatigue hysteresis loops (a); the interface slip lengths (b) versus applied stress curves corresponding to different matrix crack spacing of $l_{\mathrm{c}}=200$ and $300 \mu \mathrm{m}$. partially sliding relative to the matrix in the interface debonded region. With increasing fatigue peak stress, the fatigue stress/strain hysteresis loops area increases, and the unloading residual strain increases, as shown in Figure 3a; and the fiber/matrix interface slip lengths, i.e., $y / l_{\mathrm{d}}$ and $z / l_{\mathrm{d}}$, upon completely unloading or reloading to the maximum stress, decrease, i.e., from $y\left(\sigma_{\min }\right) / l_{\mathrm{d}}=$ $=z\left(\sigma_{\max }\right) / l_{\mathrm{d}}=0.59$ when $\sigma_{\max }=180 \mathrm{MPa}$ to $y\left(\sigma_{\min }\right) / l_{\mathrm{d}}=$ $=z\left(\sigma_{\max }\right) / l_{\mathrm{d}}=0.57$ when $\sigma_{\max }=220 \mathrm{MPa}$, as shown in Figure $3 b$.

\section{Effect of matrix crack spacing}

The effect of matrix crack spacing (i.e., $l_{c}=200$ and $300 \mu \mathrm{m}$ ) on the in-phase thermomechanical fatigue stress/strain hysteresis loops and fiber/matrix interface slip lengths at the fatigue peak stress of $\sigma_{\max }=200 \mathrm{MPa}$ and at the temperature range from $20^{\circ} \mathrm{C}$ to $800^{\circ} \mathrm{C}$ are given in Figure 4. The in-phase thermomechanical fatigue hysteresis loops for the matrix crack spacing of $l_{\mathrm{c}}=200$ and $300 \mu \mathrm{m}$ correspond to the fiber/matrix interface partially debonding and the fiber partially

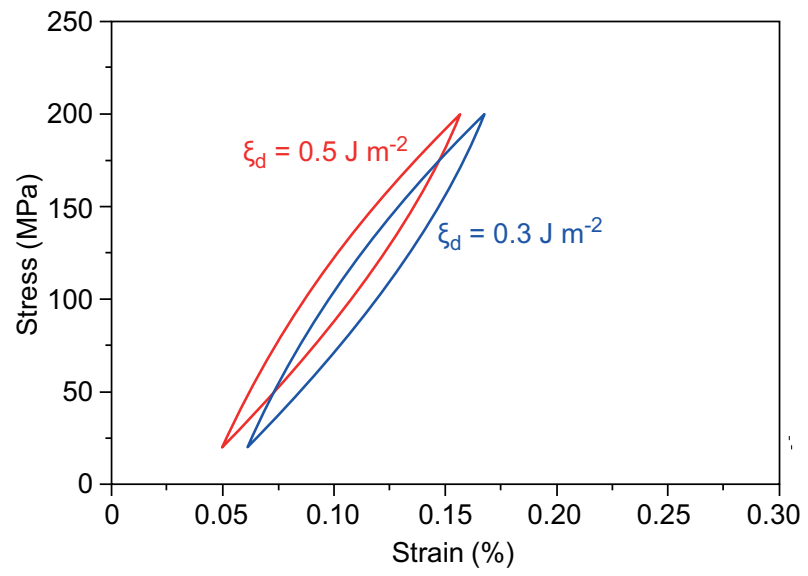

a) fatigue hysteresis loops

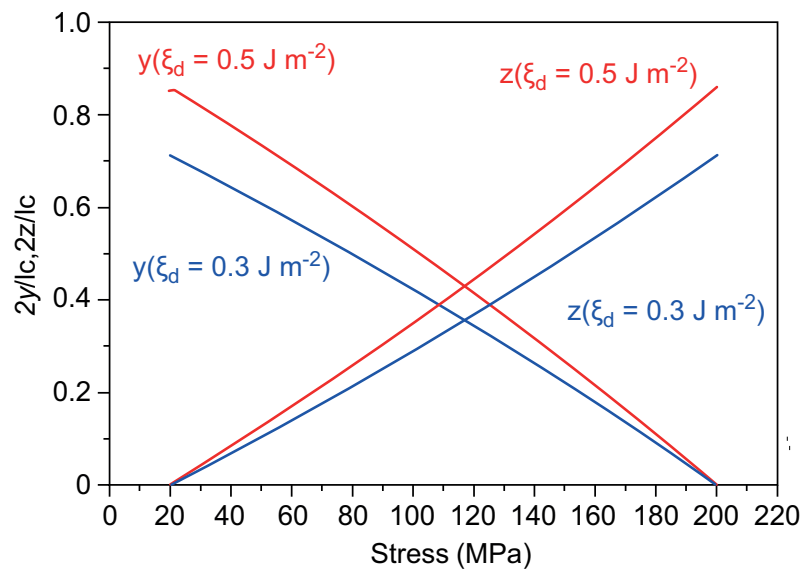

b) interface slip lengths

Figure 5. The fatigue hysteresis loops (a); the interface slip lengths (b) versus applied stress curves corresponding to different interface debonded energy of $\zeta_{\mathrm{d}}=0.3$ and $0.5 \mathrm{~J} \cdot \mathrm{m}^{-2}$. 
sliding relative to the matrix in the interface debonded region. With increasing matrix crack spacing, the inphase thermomechanical fatigue hysteresis loops area decreases, and the unloading residual strain decreases, as shown in Figure 4a; and the fiber/matrix interface slip lengths, i.e., $2 y / l_{\mathrm{c}}$ and $2 z / l_{\mathrm{c}}$, upon completely unloading or reloading to the maximum stress, decrease, i.e., from $2 y\left(\sigma_{\min }\right) / l_{\mathrm{c}}=2 z\left(\sigma_{\max }\right) / l_{\mathrm{c}}=0.8$ when $l_{\mathrm{c}}=200 \mu \mathrm{m}$ to $2 y\left(\sigma_{\min }\right) / l_{\mathrm{c}}=2 z\left(\sigma_{\max }\right) / l_{\mathrm{c}}=0.53$ when $l_{\mathrm{c}}=300 \mu \mathrm{m}$, as shown in Figure $4 b$.

\section{Effect of fiber/matrix interface debonded energy}

The effect of fiber/matrix interface debonded energy (i.e., $\zeta_{\mathrm{d}}=0.3$ and $0.5 \mathrm{~J} \cdot \mathrm{m}^{-2}$ ) on the in-phase thermomechanical fatigue stress/strain hysteresis loops and fiber/matrix interface slip lengths at the fatigue peak stress of $\sigma_{\max }=200 \mathrm{MPa}$ and at the temperature range from $20^{\circ} \mathrm{C}$ to $800^{\circ} \mathrm{C}$ are shown in Figure 5. The in-phase thermomechanical fatigue stress/strain hysteresis loops corresponding to the fiber/matrix interface debonded

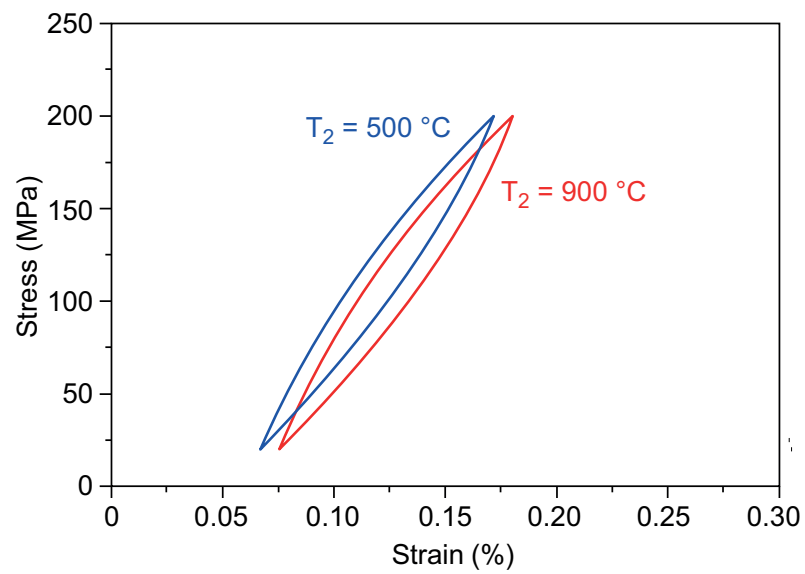

a) fatigue hysteresis loops

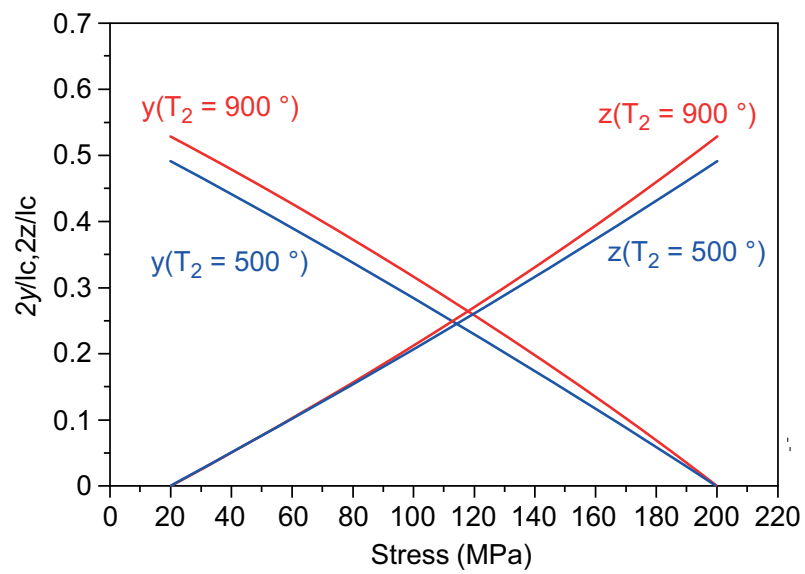

b) interface slip lengths

Figure 6. The fatigue hysteresis loops (a); the interface slip lengths (b) versus applied stress curves corresponding to testing temperature of $T_{2}=500^{\circ} \mathrm{C}$ and $900^{\circ} \mathrm{C}$. energy of $\zeta_{\mathrm{d}}=0.3$ and $0.5 \mathrm{~J} \cdot \mathrm{m}^{-2}$ correspond to the fiber/ matrix interface partially debonding and the fiber partially sliding relative to the matrix in the interface debonded region. With increasing fiber/matrix interface debonded energy, the fatigue hysteresis loops area decreases, and the unloading residual strain decreases, as shown in Figure 5a; and the fiber/matrix interface slip lengths, i.e., $y / l_{\mathrm{d}}$ and $z / l_{\mathrm{d}}$, upon completely unloading or reloading to the maximum stress, increase, i.e., from $y\left(\sigma_{\min }\right) / l_{\mathrm{d}}=$ $=z\left(\sigma_{\max }\right) / l_{\mathrm{d}}=0.71$ when $\zeta_{\mathrm{d}}=0.3 \mathrm{~J} \cdot \mathrm{m}^{-2}$ to $y\left(\sigma_{\min }\right) / l_{\mathrm{d}}=z\left(\sigma_{\max }\right) /$ $/ l_{\mathrm{d}}=0.85$ when $\zeta_{\mathrm{d}}=0.5 \mathrm{~J} \cdot \mathrm{m}^{-2}$, as shown in Figure $5 \mathrm{~b}$.

\section{Effect of thermal cyclic temperature range}

The effect of temperature range (i.e., $T_{2}=500^{\circ} \mathrm{C}$ and $900^{\circ} \mathrm{C}$ ) on the in-phase thermomechanical fatigue stress/strain hysteresis loops and fiber/matrix interface slip lengths at the fatigue peak stress of $\sigma_{\max }=200 \mathrm{MPa}$ are shown in Figure 6. The in-phase thermomechanical fatigue stress/strain hysteresis loops for the temperature range of $T_{2}=500^{\circ} \mathrm{C}$ and $900^{\circ} \mathrm{C}$ correspond to the fiber/ matrix interface partially debonding and the fiber partially sliding relative to the matrix in the interface debonded region. With increasing temperature range, the in-phase thermomechanical fatigue stress/strain hyste-resis loops area increases, and the unloading residual strain increases, as shown in Figure 6a; and the fiber/matrix interface slip lengths, i.e., $2 y / l_{\mathrm{c}}$ and $2 z / l_{\mathrm{c}}$, upon completely unloading or reloading to the maximum stress, increase, i.e., from $2 y\left(\sigma_{\min }\right) / l_{\mathrm{c}}=2 z\left(\sigma_{\max }\right) / l_{\mathrm{c}}=0.49$ when $T_{2}=500^{\circ} \mathrm{C}$ to $2 y\left(\sigma_{\min }\right) / l_{\mathrm{c}}=2 z\left(\sigma_{\max }\right) / l_{\mathrm{c}}=0.52$ when $T_{2}=900^{\circ} \mathrm{C}$, as shown in Figure $6 \mathrm{~b}$.

\section{EXPERIMENTAL COMPARISONS}

Allen and Mall [3] investigated the in-phase thermomechanical fatigue behavior of cross-ply SiC/MAS composite at the temperature range of $566^{\circ} \mathrm{C}$ and $1093^{\circ} \mathrm{C}$, with the stress ratio of 0.1 . The material properties are given by: $V_{\mathrm{f}}=40 \%, E_{\mathrm{f}}=200 \mathrm{GPa}, E_{\mathrm{m}}=$ $=138 \mathrm{GPa}, r_{\mathrm{f}}=7.5 \mu \mathrm{m}, \zeta_{\mathrm{d}}=0.1 \mathrm{~J} \cdot \mathrm{m}^{-2}, \alpha_{\mathrm{f}}=4 \times 10^{-6} /{ }^{\circ} \mathrm{C}$, $\alpha_{\mathrm{m}}=2.4 \times 10^{-6} /{ }^{\circ} \mathrm{C}, \mathrm{T}_{0}=1200^{\circ} \mathrm{C}$. The experimental fatigue hysteresis loops under $\sigma_{\max }=120 \mathrm{MPa}$ at the temperature range of $566^{\circ} \mathrm{C}$ and $1093^{\circ} \mathrm{C}$ with in-phase cyclic loading corresponding to the cycle number of $N=1,10,30,70$ and 100 are illustrated in Figure 7 11.

The in-phase thermomechancial fatigue stress/strain hysteresis loops at the cyclic number of $N=1,10,30$, 70 and 100 all correspond to the fiber/matrix interface partially debonding and the fiber partially sliding relative to the matrix in the interface debonded region; and the interface counter-slip length upon unloading to the valley stress of $\sigma_{\min }=12 \mathrm{MPa}$, and the interface new slip length upon reloading to the peak stress of $\sigma_{\max }=120 \mathrm{MPa}$, both decrease with increasing of cycle number, i.e., 


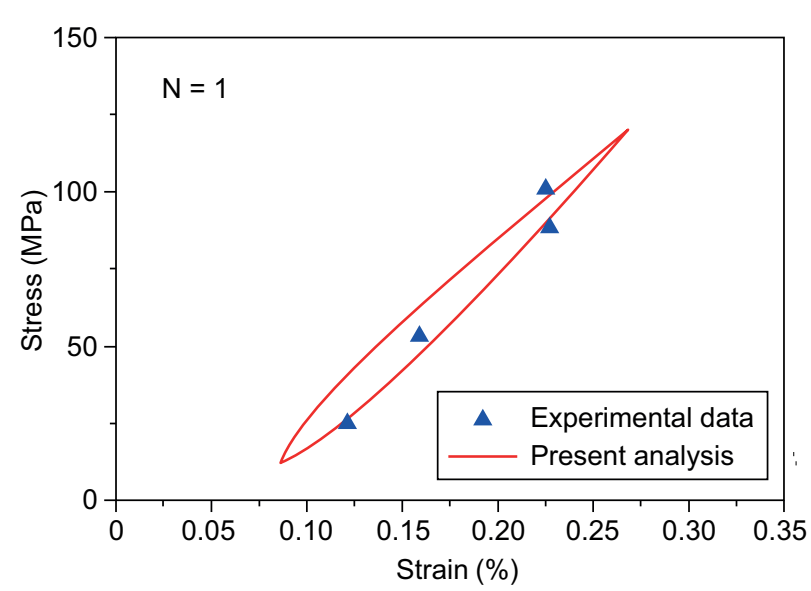

a) fatigue hysteresis loops

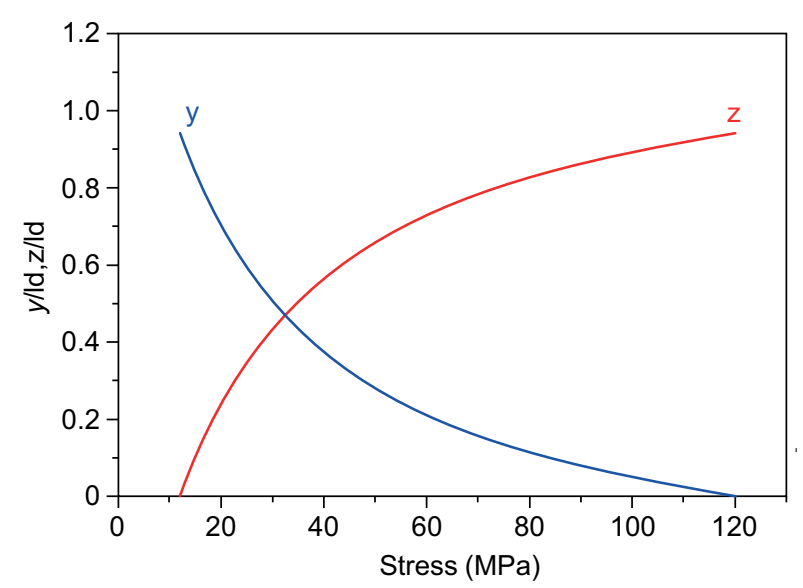

b) interface slip lengths

Figure 7. The experimental and theoretical fatigue hysteresis loops (a); and the interface slip lengths (b) versus applied stress curves of cross-ply SiC/MAS composite under in-phase thermomechanical fatigue loading with $\sigma_{\max }=120 \mathrm{MPa}$, the temperature range from $T_{1}=566^{\circ} \mathrm{C}$ to $T_{2}=1093^{\circ} \mathrm{C}$ at the $\mathrm{N}=1$.

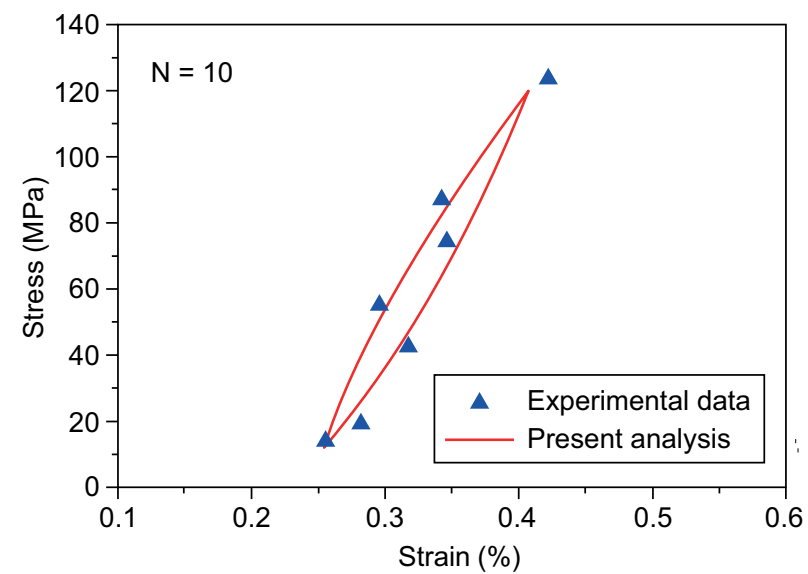

a) fatigue hysteresis loops

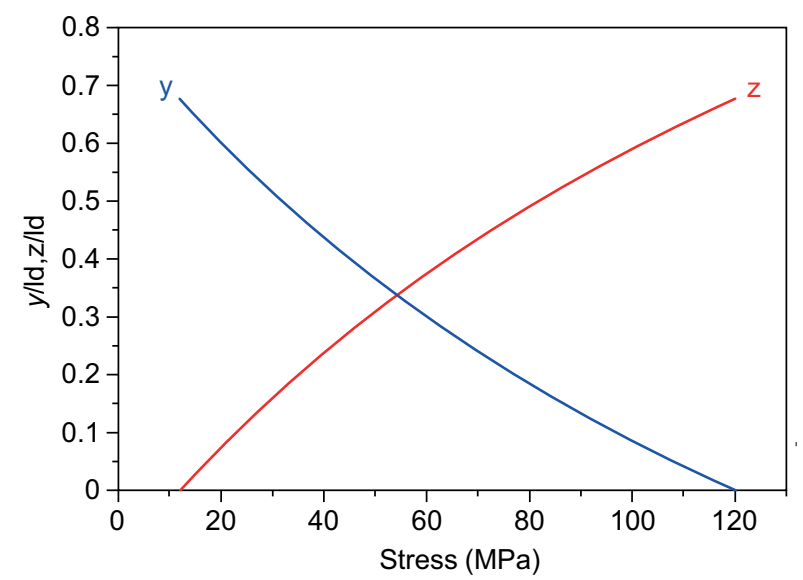

b) interface slip lengths

Figure 8. The experimental and theoretical fatigue hysteresis loops (a); and the interface slip lengths (b) versus applied stress curves of cross-ply SiC/MAS composite under in-phase thermomechanical fatigue loading with $\sigma_{\max }=120 \mathrm{MPa}$, the temperature range from $T_{1}=566^{\circ} \mathrm{C}$ to $T_{2}=1093^{\circ} \mathrm{C}$ at the $\mathrm{N}=10$.

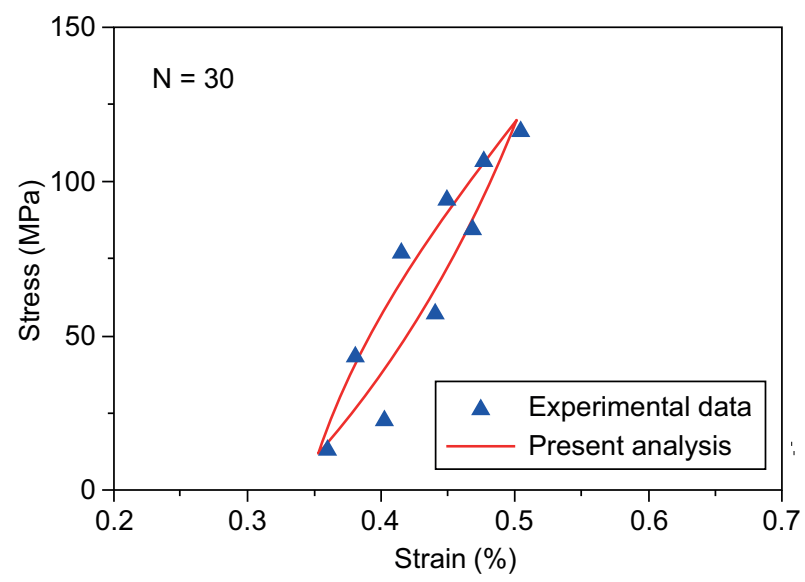

a) fatigue hysteresis loops

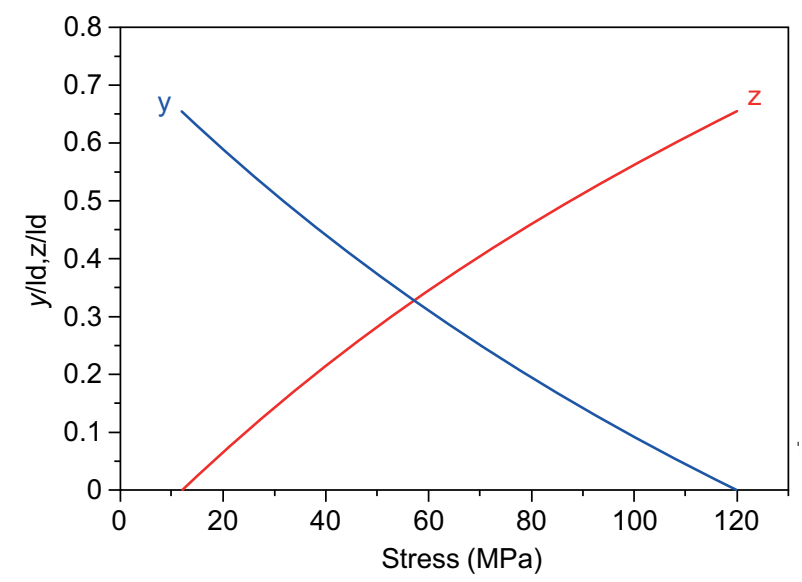

b) interface slip lengths

Figure 9. The experimental and theoretical fatigue hysteresis loops (a); and the interface slip lengths (b) versus applied stress curves of cross-ply $\mathrm{SiC} / \mathrm{MAS}$ composite under in-phase thermomechanical fatigue loading with $\sigma_{\max }=120 \mathrm{MPa}$, the temperature range from $T_{1}=566^{\circ} \mathrm{C}$ to $T_{2}=1093^{\circ} \mathrm{C}$ at the $\mathrm{N}=30$. 


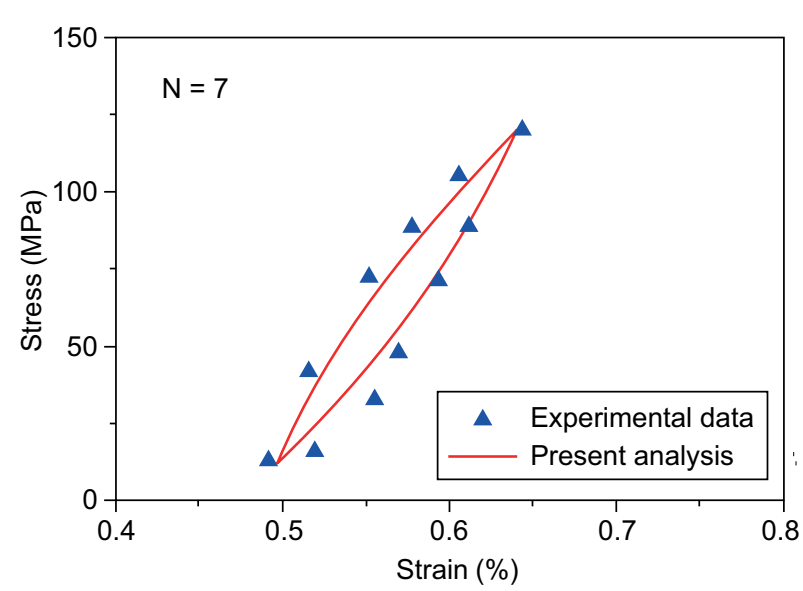

a) fatigue hysteresis loops

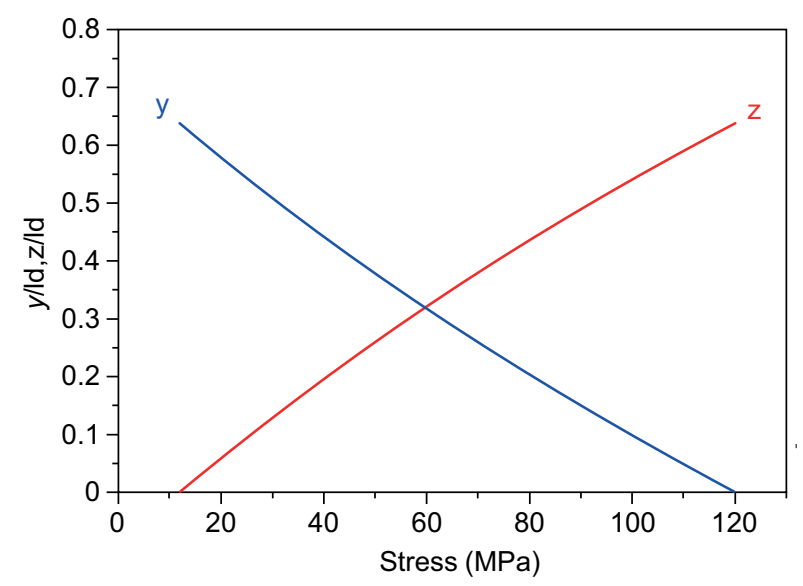

b) interface slip lengths

Figure 10. The experimental and theoretical fatigue hysteresis loops (a); and the interface slip lengths (b) versus applied stress curves of cross-ply SiC/MAS composite under in-phase thermomechanical fatigue loading with $\sigma_{\max }=120 \mathrm{MPa}$, the temperature range from $T_{1}=566^{\circ} \mathrm{C}$ to $T_{2}=1093^{\circ} \mathrm{C}$ at the $\mathrm{N}=70$.

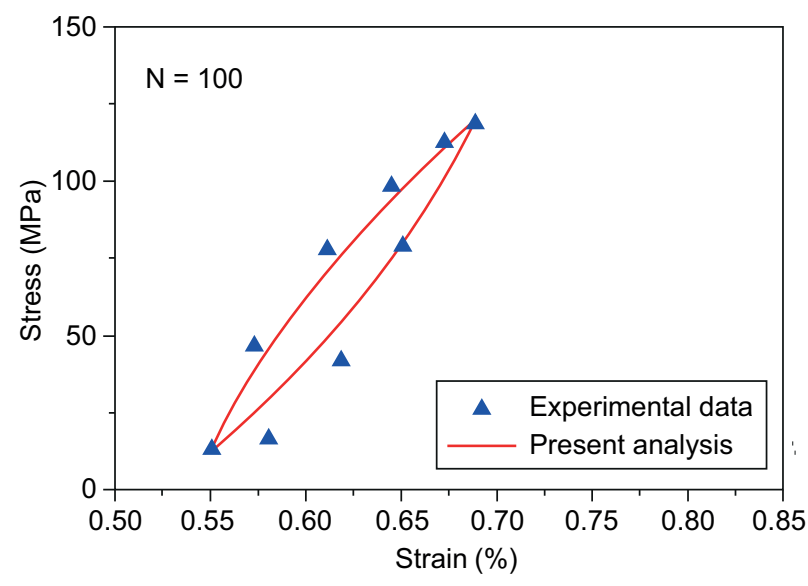

a) fatigue hysteresis loops

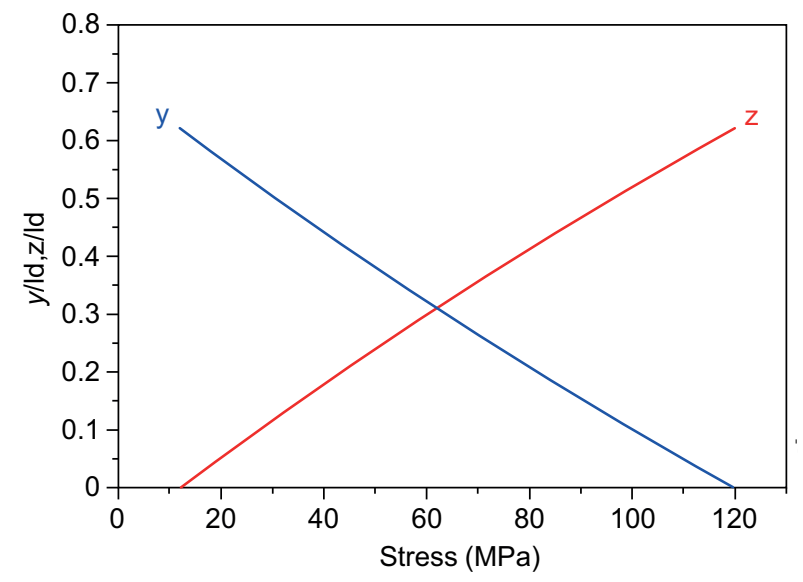

b) interface slip lengths

Figure 11. The experimental and theoretical fatigue hysteresis loops (a); and the interface slip lengths (b) versus applied stress curves of cross-ply $\mathrm{SiC} / \mathrm{MAS}$ composite under in-phase thermomechanical fatigue loading with $\sigma_{\max }=120 \mathrm{MPa}$, the temperature range from $T_{1}=566^{\circ} \mathrm{C}$ to $T_{2}=1093^{\circ} \mathrm{C}$ at the $\mathrm{N}=100$.

$y\left(\sigma_{\min }\right) / l_{\mathrm{d}}=z\left(\sigma_{\max }\right) / l_{\mathrm{d}}=0.941$ when $N=1, y\left(\sigma_{\min }\right) / l_{\mathrm{d}}=$ $=z\left(\sigma_{\max }\right) / l_{\mathrm{d}}=0.676$ when $N=10, y\left(\sigma_{\min }\right) / l_{\mathrm{d}}=z\left(\sigma_{\max }\right) / l_{\mathrm{d}}=$ $=0.655$ when $N=30, y\left(\sigma_{\text {min }}\right) / l_{\mathrm{d}}=z\left(\sigma_{\text {max }}\right) / l_{\mathrm{d}}=0.637$ when $N=70, y\left(\sigma_{\min }\right) / l_{\mathrm{d}}=z\left(\sigma_{\max }\right) / l_{\mathrm{d}}=0.621$ when $N=100$, as shown in Figures 7 11.

\section{CONCLUSIONS}

In this paper, the in-phase thermomechanical fatigue hysteresis loops of fiber-reinforced CMCs have been investigated. The effects of fiber volume fraction, fatigue peak stress, matrix cracking space, fiber/matrix interface debonded energy, and thermal cyclic temperature range on the in-phase thermomechanical fatigue stress/strain hysteresis loops have been analyzed. The in-phase thermomechanical fatigue hysteresis loops of cross-ply $\mathrm{SiC} / \mathrm{MAS}$ composite have been predicted for different applied cycle number.

With increasing fiber volume fraction, matrix crack spacing, fiber/matrix interface debonded energy, the inphase thermomechanical fatigue hysteresis loops area and the unloading residual strain decrease.

With increasing fatigue peak stress and temperature range, the in-phase thermomechanical fatigue stress/ strain hysteresis loops area and the unloading residual strain increases. 
Acknowledgements

The work reported here is supported by the Fundamental Research Funds for the Central Universities (Grant no. NS2016070).

\section{REFERENCES}

1. Li L.B. (2017): Modeling strength degradation of fiberreinforced ceramic-matrix composites under cyclic loading at room and elevated temperatures. Materials Science and Engineering: A, 695, 221-229. doi:10.1016/j.msea.2017. 04.035

2. Butkus L.M., Holmes J.W., Nicholas T. (1993): Thermomechanical fatigue behavior of a silicon carbide fiber-reinforced calcium aluminosilicate composite. Journal of the American Ceramic Society, 76, 2817-2825. doi:10.1111/ j.1151-2916.1993.tb04022.x

3. Allen D.G., Mall S. (1997): Thermo-mechanical fatigue behavior of cross-ply ceramic matrix composite under tension-tension loading. Ceramic Engineering and Science Proceedings, 18, 763-770. doi:10.1002/9780470294437.ch83

4. Xie M., Frey N., Nagar A., Foreman C. (1998). Thermomechanical fatigue testing of ceramic matrix composite plates with a hole. in: $39^{\text {th }}$ AIAA/ASME/ASCE/AHS/ASC Structures, Structural Dynamics, and Materials Conference and Exhibit.pp. 1700

5. Mei H., Cheng L.F. (2008): Thermal cycling response behavior of ceramic matrix composites under load and displacement constraints. Materials Science and Engineering: A, 486, 235-240. doi:10.1016/j.msea.2007. 09.053

6. Kim, T.T., Mall, S., Zawada, L.P. (2009). Thermomechanical and fatigue testing of woven and prepreg MI Hi-Nic-S/BN/ $\mathrm{SiC}$ ceramic matrix composites (CMCs) using a unique combustion materials test facility. in: The 17th International Conference on Composite Materials. pp. 27-31.

7. Cluzel C., Baranger E., Ladeveze P., Moure, A. (2009):
Mechancial behavior and lifetime modeling of self-healing ceramic-matrix composites subjected to thermomechanical loading in air. Composites Part A, 40, 976-984. doi:10.1016/ j.compositesa.2008.10.020

8. Reynaud P., Douby D., Fantozzi G. (1998): Effects of temperature and of oxidation on the interfacial shear stress between fibers and matrix in ceramic-matrix composites. Acta materialia, 46(7), 2461-2469. doi:10.1016/S13596454(98)80029-3

9. Li L.B. (2015): Tension-tension fatigue behavior of unidirectional $\mathrm{C} / \mathrm{SiC}$ ceramic-matrix composite at room temperature and $800^{\circ} \mathrm{C}$ in air atmosphere. Materials, 8, 3316-3333. doi:10.3390/ma8063316

10. Li L.B. (2017): Comparisons of interface shear stress degradation rate between $\mathrm{C} / \mathrm{SiC}$ and $\mathrm{SiC} / \mathrm{SiC}$ ceramicmatrix composites under cyclic fatigue loading at room and elevated temperatures. Composite Interface, 24, 171-202. doi:10.1080/09276440.2016.1196995

11. Li L.B. (2015): Micromechanical modeling for fatigue hysteresis loops of fiber-reinforced ceramic-matrix composites under multiple loading stress levels. International Journal of Applied Mechanics, 7, 1550087. doi:10.1142/ S1758825115500878

12. Li L.B. (2015): Synergistic effect of arbitrary loading sequence and interface wear on the fatigue hysteresis loops of carbon fiber-reinforced ceramic-matrix composites. Engineering Fracture Mechanics, 146, 67-88. doi:10.1016/ j.engfracmech.2015.07.060

13. Li L.B. (2017): Damage evolution of cross-ply ceramicmatrix composites under stress-rupture and cyclic loading at elevated temperatures in oxidizing atmosphere. Materials Science and Engineering: A, 688, 315-321. doi:10.1016/j. msea.2017.02.012

14. Li L.B. (2016): Damage development in fiber-reinforced ceramic-matrix composites under cyclic fatigue loading using hysteresis loops at room and elevated temperatures. International Journal of Fracture, 199, 39-58. doi:10.1007/ s10704-016-0085-y 